\title{
A problemática da Antropologia Teológica
}

\author{
Francisco de Aquino Júnior
}

\section{Resumo}

O artigo aborda a problemática da Antropologia Teológica. É uma tentativa de explicitar o estatuto teórico de uma das mais recentes e mais relevantes disciplinas ou áreas da teologia. Ela trata da respectividade e relação do ser humano com Deus a partir da vida de Jesus de Nazaré que é para os cristãos o lugar da revelação plena e definitiva do mistério de Deus e do mistério do ser humano. Começa tratando da origem, do contexto, dos riscos e dos fundamentos teológicos dessa disciplina. Aborda, em seguida, a problemática de seu estatuto teórico e, ligado a isso, suas dificuldades e seus desafios epistemológicos. E conclui chamando atenção para o fato da tão falada crise da modernidade não significar sem mais uma crise da dimensão antropológica da teologia nem consequentemente dessa área ou disciplina que a antropologia teológica.

Palavras-Chave: Antropologia Teológica; Dimensão; Cristologia.

\section{Abstract}

The article examines the question of Theological Anthropology. It is an attempt to describe the theoretic status of one of the most recent and relevant 
disciplines or areas of theology. It deals with the relationship of human beings with God, from the starting point of the life of Jesus of Nazareth. This life is, for Christians, the locus of the complete and definite revelation, both of the mystery of God and the mystery of the human person. It begins by looking at the origin, the context, the risks and the theological underpinnings of this discipline. Later it treats of the problematic of its theological status and, linked to this question, the difficulties and epistemological challenges it faces. The article concludes by calling attention to the fact that the much talkedabout crisis of modernity means no more than a crisis of the anthropological dimension of theology or, consequently, a crisis for this area or discipline known as theological anthropology.

Keywords: Theological Anthropology; Area; Christology.

\section{Introdução}

A disciplina Antropologia Teológica $(A T)$ é muito recente no estudo da teologia e, como tal, é, de maneira particular, uma disciplina em construção. Se a teologia pós-conciliar em seu conjunto vive uma "situação de busca", isso vale de modo especial para uma disciplina tão recente como a $A T$, sobretudo se considerarmos, por um lado, a importância e centralidade da antropologia no mundo moderno e, por outro lado, a dificuldade moderna de uma abordagem estritamente teológica da antropologia. Mais ainda se considerarmos a tão falada crise da modernidade e da teologia moderna. Daí o caráter particularmente problemático dessa disciplina. Ele nos lança na tarefa de determinarmos e explicitarmos seu estatuto teórico, enfrentando, para isto, as dificuldades epistemológicas provenientes tanto do contexto em que vivemos quanto do próprio quefazer teológico enquanto tal.

E é precisamente com essa problemática que nos confrontaremos neste artigo. Começaremos falando da $A T$ como disciplina para abordarmos, em seguida, a problemática de seu estatuto teórico e, ligado a isso, suas dificuldades e seus desafios epistemológicos. São os três pontos de nossa reflexão em torno da problemática da $A T$.

${ }^{1}$ Cf. H. RITO, Introdução à teologia. Vozes, Petrópolis, 1999, p. 17. 


\section{I - Antropologia Teológica como disciplina}

1. Antes de tudo, convém advertir e insistir no fato de que a $A T$ como disciplina é relativamente recente no estudo da teologia: "surgiu ou ao menos explodiu no início da década de sessenta"2. É o que se pode constatar, por exemplo, na afirmação de Karl Rahner, uma referencia fundamental em se tratando de $A T$, em um artigo publicado em 1957 e intitulado precisamente de Antropologia Teológica: "A construção propriamente dita de uma antropologia (teológica) ainda não aconteceu. A antropologia ainda é repartida nos diferentes tratados, sem uma elaboração do fundamento sistemático de sua totalidade. A antropologia, no sentido aqui indicado, é ainda uma tarefa não realizada pela teologia, naturalmente não no sentido de que as afirmações concretas e de conteúdo dessa antropologia ainda devam ser encontradas pela primeira vez - trata-se evidentemente de afirmações da revelação sobre o homem -, mas sim no sentido de que a teologia católica ainda não desenvolveu nenhuma antropologia completa partindo de um ponto de vista originário"3. Como se vê, a expressão $A T$ aparece, aqui, como "o nome de uma disciplina ainda não existente naquele momento, cuja elaboração, porém, aos poucos se mostra necessária"4.

Certamente, a problemática antropológica sempre esteve presente e de modo muito central na teologia 5 . Ela sempre se ocupou da vida humana em sua relação com Deus: criação, pecado, graça, santificação, salvação, condenação etc. "Não se pode negar que o ser humano sempre ocupou um lugar central na reflexão sobre a fé e foi o objeto máximo de preocupação pastoral da Igreja" ${ }^{\circ}$, ainda que essa centralidade e essa preocupação tenham recebido uma formulação distinta de sua formulação atual. Neste sentido, a abordagem teológica da antropologia não é algo absolutamente novo. Como veremos mais adiante, é algo que diz respeito à identidade mais profunda da teologia e, enquanto tal, tem a idade da teologia.

\footnotetext{
${ }^{2}$ U. VÁZQUEZ MORO, “Teologia e antropologia: aliança ou conflito?”, Perspectiva Teológica 60 (1991) PP. 163-174, aqui p. 163; Cf. F. ELISONDO, "Antropologia”. In: C. FLORISTÁNSAMANES - J.J. TAMAYO-ACOSTA, Dicionário de Conceitos Fundamentais do Cristianismo. Paulus, São Paulo, 1999, pp. 23-32, aqui pp. 30s; F.G. BRAMBILLA, Antropologia teologica. Queriniana, Brescia, 2009, PP. 17s.

${ }^{3}$ K. RAHNER, "Anthropologie, theologische Anthropologie". Apud L. F. LADARIA, Introdução à antropologia teológica. Loyola, São Paulo, 1998, p. 24.

${ }^{4}$ L.F. LADARIA, Luis. Op. cit.. p. 24.

${ }^{5}$ Cf. Ibidem, 16-36; M. FLICK - Z. ALSZEGHY, Fondamenti di una Antropologia Teológica. Fiorentina, Firenze, 1982, p. 3; F. ELISONDO, Felisa. Op. cit., pp. 30s.

${ }^{6}$ L.F. LADARIA, Antropologia teológica. UPCM, Madrid - PUG, Roma, 1983, p. 1.
} 
No entanto, como constatava Rahner ainda no final dos anos 50, não havia na teologia uma elaboração sistemática da realidade humana em sua respectividade e relação com Deus. Os assuntos ou temas mais diretamente referidos ao ser humano estavam fragmentados e repartidos em "diferentes tratados" (criação, pecado, graça etc.). "A preocupação no campo teológico por agrupar em torno a esse centro de interesse as matérias que tratam dos vários aspectos da ação criadora e salvadora de Deus é relativamente nova"7.

Daí a importância de começar nossa discussão sobre a problemática da $A T$ distinguindo a antropologia com problema teológico da antropologia como disciplina teológica. Se esta é muito recente, aquela é uma constante no estudo da teologia.

2. A necessidade e o esforço de uma reflexão teológica sistemática sobre o ser humano e, ligado a isso, o surgimento da disciplina $A T$ só podem ser compreendidos a partir do contexto que os provocam, em que surgem e ao qual procuram responder ${ }^{8}$. Sem entrar em maiores especulações e precisões teóricas, podemos nos referir a esse contexto nos termos de modernidade ou de mundo moderno, tomando como sua característica fundamental a concentração antropológica do pensamento, formulada e expressa nas clássicas perguntas de Kant: “O que posso saber?”; "O que devo fazer?"; "O que me é permitido esperar?"; "O que é o homem?".

A característica fundamental do pensamento moderno é pensar todas as "coisas", inclusive Deus, a partir de e/ou em respectividade ao homem, ainda que esse homem possa ser compreendido de maneiras muito diferentes: aberto a Deus ou fechado sobre si mesmo e seu mundo ${ }^{10}$. Em todo caso, como

\footnotetext{
${ }^{7}$ Ibidem.

${ }^{8}$ Cf. F. ELISONDO, Op. cit., pp. 23ss; F.G. BRAMBILLA, Op. cit., pp. 16ss, p. 36; W. PANNENBERG, Anthropologie in theologischer Perspective. Vandenhoeck \& Ruprecht, Göttingen, 1983, pp. 11-23: IDEM. Was ist der Mensch? Die Anthropologie der Gegenwart im Lichte der Theologie. Vandenhoeck \& Ruprecht, Göttingen, 1995, pp. 5-13; B. MONDIN, Antropologia teológica: história, problemas, perspectivas. Paulinas, São Paulo, 1986, pp. 29-44.

${ }^{9}$ Cf. I. KANT, Crítica da razão pura. Nova Cultural, São Paulo, 1996, p. 478 (Os Pensadores); IDEM, Lógica. Tempo brasileiro, Rio de Janeiro, 2003, p. 42.

${ }^{10}$ Enquanto Lima Vaz tende a ver na modernidade a "abolição da estrutura onto-teólogica" do pensar e sua "substituição por uma estrutura onto-antropológica", na qual "um novo sol filosófico reorganiza na sua órbita o sistema das razões que passará a dominar na sociedade" (H. LIMA VAZ, "Religião e modernidade filosófica", Síntese Nova Fase 53 [1991] pp. 147-165, aqui pp. 154s); Manfredo Oliveira, sem negar que essa é uma das tendências da modernidade, insiste em que "a modernidade não foi só isso" e afirma que "a modernidade filosófica se pode entender, também, como o esforço de reestruturação da filosofia enquanto teologia racional a partir das exigências que emergiam do novo contexto cultural". E faz isso, precisamente, no prefácio de um
} 
reconhece o próprio Kant no prefácio à segunda edição da Crítica da Razão Pura, isso significou uma verdadeira "revolução copernicana" no pensamento $^{11}$. Fala-se, neste contexto, da passagem de um "teocentrismo" para um "antropocentrismo"12 ou da passagem de um esquema "onto-teológico" para um esquema "onto-antropológico" do pensar ${ }^{13}$.

Aos poucos, essa "revolução copernicana" vai se impondo e dominando todos os âmbitos da vida e, consequentemente, todas as áreas do saber. "A última disciplina envolvida na transformação antropológica foi a teologia"14. Mas, apesar de todas as resistências e reticências e ainda que muito tardiamente ${ }^{15}$, ela teve que se confrontar com esse fenômeno e assumir, a seu modo, a reviravolta antropológica do pensar. Segundo Ladaria, "o interesse que o homem desperta no momento presente em diferentes campos da ciência tem uma correspondência muito clara na teologia [...]. Por isso entrou na linguagem da teologia a expressão 'antropologia teológica', disciplina que englobaria os diversos ensinamentos sobre o homem antes dispersos em diferentes tratados" ${ }^{\prime 16}$. Na mesma direção vai a afirmação de Pannenberg: "O ambiente espiritual geral dos tempos modernos e seu desenvolvimento [...] se reflete na concentração da problemática fundamental da teologia moderna sobre a compreensão do homem [...]. A

livro que tem como título O Deus dos filósofos modernos e em confronto explícito com a posição de Lima Vaz acima referida (M.A. OLIVEIRA - C. ALMEIDA, O Deus dos filósofos modernos. Vozes, Petrópolis, 2002, pp. 8s).

11 "Até agora se supôs que todo nosso conhecimento tinha que se regular pelos objetos [...] tente-se ver se não progredimos melhor nas tarefas da metafísica admitindo que os objetos têm que se regular pelo nosso conhecimento [...]. O mesmo aconteceu com os primeiros pensamentos de Copérnico que, depois das coisas não quererem andar muito bem com a explicação dos movimentos celestes admitindo-se que todo o exército dos astros girava em torno do espectador, tentou-se ver se não seria mais bem sucedido se deixasse o espectador mover-se e, em contrapartida, os astros em repouso. Na metafísica pode-se então tentar algo similar no que diz respeito à intuição dos objetos": em vez da "intuição" ser regulada pela "natureza do objeto", o "objeto" passa a ser regulado pela "natureza de nossa faculdade de intuição" (I. KANT, Crítica da razão pura. Op. cit., pp. 35-51, aqui p. 39).

12 "Na história do pensamento ocidental registraram-se duas grandes transições: a do cosmo para Deus e a de Deus para o homem. A primeira realizou-se quando o cristianismo suplantou a visão grega da realidade [...] A segunda grande mudança ocorreu na época moderna em consequência da secularização e do ateísmo: repentinamente Deus desaparece de cena e cede lugar ao homem [...] Costumamos chamar a primeira transformação de teocêntrica e a segunda de antropocêntrica ou antropológica" (B. MONDIN, Op. cit., p. 29).

${ }^{13}$ Cf. H.C. LIMA VAZ, Op. cit., pp. 154ss.

${ }^{14}$ B. MONDIN, Op. cit., p. 32.

${ }^{15}$ A propósito das razões ou causas desse retardamento, cf. F.G. BRAMBILLA, Op. cit., pp. 37ss.

${ }^{16}$ L.F. LADARIA, Op. cit., p. 1. 
concentração da filosofia moderna no homem como sujeito de toda experiência bem como da própria reflexão filosófica deve repercutir na teologia"17. E Felisa Elisondo fala explicitamente de "virada antropológica da teologia". Assim como se fala de "virada antropológica" na filosofia, diz ela, "pode-se dizer que a teologia registrou também sua "virada antropológica" "18.

3. Essa "virada antropológica" não deixa de ser um risco para a teologia ${ }^{19}$. Risco de um reducionismo antropológico a determinados aspectos ou dimensões da vida humana em prejuízo de sua dimensão propriamente teologal. Numa palavra: risco de um antropocentrismo autossuficiente e fechado a Deus. Por ai vão alguns receios, resistências, advertências e mesmo condenações da teologia de Karl Rahner $^{20}$, a cujo nome aparece sempre vinculada a chamada "virada antropológica" da teologia católica ${ }^{21}$, e da teologia da libertação ${ }^{22}$, embora, aqui, o centro não seja mais o homem em geral, mas "o homem pobre". Em todo caso, ambas as teologias teriam embarcado, de modo mais ou menos crítico, na "rota antropocentrizante do espírito moderno", com sérios riscos para o quefazer e para o produto teológicos ${ }^{23}$. Nem mesmo o Concílio Vaticano II escapou dessa suspeita ${ }^{24} \ldots$

${ }^{17}$ W. PANNENBERG, Anthropologie in theologischer Perspective. Op. cit., p. 12.

${ }^{18}$ F. ELISONDO, Op. cit., p. 27.

${ }^{19}$ Cf. W. PANNENBERG, Op. cit., pp. 15s; B. MONDIN, Op. cit., pp. 36ss; C. BOFF, Teoria do método teológico. Vozes, Petrópolis, 1998, pp. 113s; IDEM, "Teologia da libertação e volta ao fundamento", REB 268 (2007) pp. 1001-1022, aqui pp. 1008-1010.

${ }^{20} \mathrm{O}$ tom e a intensidade das críticas a Karl Rahner variam muito. Uma crítica mais ponderada pode-se encontrar, por exemplo, nos textos de Clodovis Boff acima referidos. Ele reconhece que a "virada antropológica" operada na "teologia transcendental" de Rahner "teve seus êxitos", mas adverte que diante dessa teologia "grandes teólogos como De Lubac, Von Balthasar e Ratzinger, mantiveram uma distância suspeitosa - sem contudo proceder a uma crítica cerrada ( Ibidem, 1009). Uma crítica mais dura e radical pode-se encontrar, por exemplo, em Cornélio Fabro (Cf. C. FABRO, Karl Rahner e l'ermeneutica tomista. La risoluzione-dissoluzione della metafísica nell'antrpologia. Editrice Divus Thomas, 1972; IDEM, La svolta antropológica di Karl Rahner. Rusconi, Milano, 1974; B. MONDIN, Op. cit., pp. 36-41). Para ele, como afirma Mondin, "as consequências lógicas da posição gnosiológica de Rahner são o imanentismo, o historicismo, o horizontalismo, a negação da metafísica e da transcendência” (Ibidem, p. 40).

${ }^{21}$ Cf. P. EICHER, Die anthropologische Wende. Karl Rahners philosophischer Weg vom Wesen des Menschen zur personalen Existez. Universitätsverlag, Freiburg, 1970; C. BOFF, Op. cit., pp. 1008s; B. MONDON, Op. cit., pp. 33-36.

${ }^{22}$ Cf. J. RATZINGER - V. MISSORI, A fé em crise? O Cardeal Ratzinger se interroga. EPU, São Paulo, 1985, pp. 131-148; J.L. SEGUNDO, “Críticas y autocríticas de la teología de la liberación”. In: J. COMBLIN - J.I. GONZÁLEZ FAUS - J. SOBRINO, Cambio social y pensamiento cristiano en América Latina. Trotta, Madrid, 1993, pp. 215-236, aqui pp. 217-221; C. BOFF, Op. cit., p. 1009. ${ }^{23}$ Cf. C. BOFF, Op. cit., p. 1009.

${ }^{24}$ Suspeita que aparece já durante o Concílio e que se intensifica no período pós-conciliar. No que diz respeito à suspeita durante o Concílio, convém reler o discurso do papa Paulo VI em 
Sem dúvida, esse é um risco ou mesmo uma tendência do pensamento moderno em gera ${ }^{25} \mathrm{e}$, certamente, não deixa de ser um risco para a reflexão teológica desenvolvida nesse contexto. Mas, além de ser um risco inevitável, dado o caráter contextual de toda teologia, é um risco que não compromete necessariamente a identidade teológica da teologia, vale a redundância, uma vez que diz respeito a algo que pertence ao núcleo mais profundo e radical da realidade que a teologia procura inteligir. E, neste sentido, é também inevitável.

Trata-se, portanto, de um risco duplamente inevitável para o quefazer teológico: inevitável, se a teologia quiser cumprir com sua tarefa de inteligência da fé no mundo moderno (caráter contextual da teologia) ${ }^{26}$; mas inevitável, sobretudo, porque a realidade que a teologia procura inteligir, isto é, a história da salvação ou o reinado de Deus, tem a ver necessária e constitutivamente com o ser humano (caráter soteriológico da revelação e da fé cristãs) ${ }^{27}$.

sua última sessão, no dia 07 de dezembro de 1965 (Cf. PAULO VI, "Discurso pronunciado na nona sessão conciliar”. In: VATICANO II, Mensagens, discursos e documentos. Paulinas, São Paulo, 2007, pp. 118-125). Reagindo às críticas e acusações de que o Concílio teria se ocupado muito pouco das "verdades divinas" (Ibidem, p. 120) ou, mesmo, que teria sido "irreligioso ou antievangélico" (Ibidem, p. 121), que teria se deixado "influenciar pela cultura contemporânea, exclusivamente voltada para o ser humano" (Ibidem, p. 123s), enfim, que a Igreja, no Concílio, teria se "desviado" de seus objetivos e de sua missão (Ibidem, p. 124), Paulo VI, além de destacar a "visão teocêntrica ou teológica" que o Concílio tem do ser humano e do mundo (Ibidem, p. 120), afirma sem meias palavras: "A Igreja não se desviou de seus objetivos. [...] em nenhum momento perdeu seu caráter estritamente religioso [...]. Voltando-se para o mundo e para os seres humanos, a Igreja não deixa de estar orientada para o Reino de Deus", uma vez que, se por um lado, "para conhecer a verdade do ser humano, na sua totalidade, é preciso se colocar do ponto de vista de Deus", por outro lado, "se lembrarmos que no rosto de todos os seres humanos, especialmente quando marcados pelas lágrimas e pela dor, brilha a face de Cristo [...] e que na face de Cristo se deve reconhecer o rosto do Pai celeste", podemos e devemos dizer também que "é preciso conhecer o ser humano para conhecer a Deus" (Ibidem, p. 124). Já no que diz respeito às suspeitas levantadas sobre certas interpretações do Concílio, valeria a pena reler a longa entrevista que o então cardeal Ratzinger concedeu ao repórter italiano Messori, na qual faz um balanço bastante pessimista dos anos pós-conciliares (Cf. J. RATZINGER - V. MESSORI, Op. cit.), bem como a reação crítica de vários teólogos latino-americanos à sua posição (Cf. J.O. BEOZZO (org.), O Vaticano II e a Igreja latino-americana. Paulinas, São Paulo, 1985).

${ }^{25} \mathrm{Cf}$. nota 10.

${ }^{26}$ Para Rahner, aqui está a preocupação fundamental e a mola propulsora da teologia em todos os tempos: "Proporcional ao homem, a partir da compreensão que ele tem de si mesmo e de seu ser nas diferentes épocas, o acesso à realidade de fé tem sido a preocupação constante da teologia, e essa preocupação é propriamente a força propulsora da teologia desde os primórdios" (K. RAHNER, "Reflexões fundamentais sobre a antropologia e a protologia no conjunto da teologia". In: J. FEINER - M. LOEHRER, Mysterium Salutis II/2. Vozes, Petrópolis, 1972, pp. 6-19, aqui p. 6). ${ }^{27}$ É também a insistência de Rahner ao justificar a "necessidade duma dimensão transcendental antropológica da teologia" a partir do próprio "objeto da teologia": 1. "A revelação é revelação 
De modo que, embora não se possa entender a concentração antropológica da teologia nas últimas décadas nem muito menos o surgimento da disciplina $A T$ sem considerar a "revolução copernicana" no pensamento ocidental, tampouco se pode tomá-las como mero reflexo da cultura moderna nem muito menos fundamentá-las e justificá-las simplesmente a partir do ambiente espiritual em que se desenvolvem e ao qual, de alguma maneira, procuram responder ${ }^{28}$. Primeiro, porque não se trata de uma antropologia qualquer, entre as muitas desenvolvidas no mundo moderno, mas de uma antropologia teológica, portanto, constitutivamente aberta e referida a Deus $^{29}$, na qual o homem é compreendido fundamentalmente como "ouvinte da palavra", para usar a expressão com a qual Rahner intitula seu estudo sobre os "fundamentos para uma filosofia da religião" 30 . Segundo, porque a centralidade do ser humano na teologia se fundamenta, em última instância, no fato de que a história da salvação ou a realização histórica do reinado de Deus, assunto da teologia, diz respeito não simplesmente a Deus, mas também às pessoas e aos povos a quem Deus salva ou sobre quem ele reina.

salvífica; logo a teologia é essencialmente teologia da salvação"; e "a importância salvífica dum objeto da teologia [...] somente pode ser inquirida, perguntando-se simultaneamente pela receptividade salvífica do homem para com esse objeto". De modo que "o objeto adquire significação teológica somente a partir desta receptividade salvífica e com vistas à mesma"; 2 . Tudo isso diz respeito ao "núcleo central" da teologia que é a "autocomunicação" de Deus enquanto "nossa salvação" (Ibidem, 9s). E isso foi assumido por muitos outros teólogos (Cf. M. FLICK - Z. ALSZEGHY, Op. cit., p. 4; W. PANNENBERG, Op. cit., p. 12; F.G. BRAMBILLA, Op. cit., p. 16; F. LISONDO, Op. cit., pp. 27ss).

${ }^{28}$ Convém distinguir, aqui, com Ignácio Ellacuria, "origem" e "princípio". O fato da concentração antropológica na teologia e do surgimento da disciplina AT terem sua "origem" na reviravolta antropológica que caracteriza o mundo moderno, não transforma sem mais essa reviravolta no "principio" estruturador fundamental da teologia. Afinal, como bem afirma Ellacuria, ainda que em outro contexto, "não toda origem se converte em princípio, nem todo processo é assumido sem mais na estrutura" (I. ELLACURÍA, "En torno al concepto y a la idea de liberación". In. IDEM, Escritos Teológicos I. UCA, San Salvador, 2000, pp. 629-657, aqui p. 631). Se essa reviravolta antropológica pôde se dar também na teologia, isso se deve, em última instância, ao fato de la tocar ou dizer respeito ao princípio fundamental mesmo da teologia, enquanto inteligência da história da salvação. ${ }^{29}$ Daí a insistência de Rahner de que sua tese da "antropologia como lugar da teologia", uma tese fundamental de sua teologia, "não contradiz ao teocentrismo da teologia [...], visto que toda teologia, inclusive a doutrina sobre Deus, nada pode afirmar sem com isso dizer igualmente algo sobre o homem e vice-versa". Mas a antropologia é entendida já num sentido fundamentalmente teológico: "Se o homem, em razão de sua transcendência, é o ser voltado perene e excentricamente para Deus e, consequentemente [...], ele é a possível alteridade de Deus, segue-se que o lugar universal de toda teologia é a antropologia" (K. RAHNER, Op. cit., p. 6.). E, aqui, ele se contrapõe explicitamente ao antropocentrismo antiteológico de Feuerbach.

${ }^{30}$ IDEM, Oyente de la palabra. Fundamentos para una filosofia de la religión. Herder, Barcelona, 1976. 
De modo que a antropologia, neste contexto, mais que uma disciplina ou área da teologia, aparece como uma dimensão constitutiva de toda a teologia cristã $^{31}$. Foi a grande intuição e contribuição de Rahner para teologia em geral e para a disciplina $A T$ em particular ${ }^{32}$.

E com isso tocamos diretamente na problemática do estatuto teórico da $A T$ como disciplina, isto é, naquilo que a constitui como tal frente a outras antropologias (biológica, psicológica, cultural, social etc.) e frente a outras áreas ou disciplinas teológicas (trindade, eclesiologia, liturgia etc.), por mais que ela não possa prescindir nem das outras antropologias nem das outras áreas ou disciplinas teológicas. É o próximo ponto de nossa reflexão.

\section{II - Estatuto Teórico da disciplina Antropologia Teológica}

Começamos chamando atenção para o fato da "concentração antropológica" na teologia e, ligado a isso, do surgimento da disciplina $A T$ ser muito recente na história da teologia. Situamos esse fato no contexto mais amplo da "virada antropológica" que caracteriza o mundo moderno. E concluímos advertindo tanto acerca dos riscos que esse fato comporta para a teologia (reducionismo antropológico), quanto acerca de sua inevitabilidade (caráter contextual e caráter soteriológico da teologia). Tratando do caráter soteriológico da teologia, distinguimos dois aspectos fundamentais e complementares: caráter teológico da antropologia (antropologia teológica) e caráter antropológico da teologia (teologia antropológica). E com isso, indicávamos, entramos de cheio na problemática do estatuto teórico da disciplina $A T$ : o ser humano em sua respectividade e relação com Deus, tal como ele se revelou na história de Israel e, nela, de modo definitivo, na vida/práxis de Jesus de Nazaré.

\footnotetext{
${ }^{31}$ Cf. K. RAHNER, Teologia e antropologia. Paulinas, São Paulo, 1969, p. 13; M. FLICK - Z. ALSZEGHY, Op. cit., p. 4; W. PANNENBERG, Op. cit., p. 12.

${ }^{32}$ É famosa a conferência de Rahner num congresso de teologia em Chicago, em 1966, intitulada Teologia e antropologia. As primeiras palavras de Rahner nesta conferência, considerada uma espécie de manifesto, deixam clara não apenas sua pretensão naquele momento, mas a pretensão de todo seu labor teológico e seu aporte para o conjunto da teologia: "Esta exposição desejaria convencer que a teologia dogmática deve tornar-se hoje uma antropologia teológica, que este 'antropocentrismo' é necessário e fecundo [...] A tese não contradiz o caráter teocêntrico de toda teologia [...]. Desde que se considere o homem como absoluta transcendência orientada para Deus, o 'antropocentrismo' e o 'teocentrismo' da teologia não se contradizem, mas formam rigorosamente uma única e mesma coisa, expressa a partir de dois pontos de vista" (K. RAHNER, Op. cit., p. 12).
} 
Essa problemática aparece formulada de modo muito condensado no primeiro parágrafo da introdução geral do livro de Introdução à antropologia teológica de Ladaria. O texto é um pouco longo, mas vale a pena transcrever:

Pode-se falar do homem, e de fato se fala, sob muitos pontos de vista: filosófico, psicológico, médico, sociológico... O termo 'antropologia' tornou-se em muitos casos um termo equívoco. É evidente que a palavra nos remete ao homem, nos mostra que ele é o objeto material de nosso estudo. Mas isso não basta; precisamos deixar claro, e isso sem dúvida é muito importante, o ponto de vista a partir do qual procuramos abordá-lo. O adjetivo 'teológica' diz-nos qual é esse ponto de vista: trata-se do que o homem é em sua relação com o Deus Uno e Trino revelado em Cristo. Ao mesmo tempo, indica-nos, pelo menos em linhas gerais, o método que precisamos seguir para alcançar o objetivo: o estudo da revelação cristã. Procuremos introduzir-nos na 'antropologia teológica', ou seja, naquela disciplina ou, melhor ainda, naquela parte ou setor da teologia dogmática que nos ensina o que somos à luz de Jesus Cristo revelador de Deus ${ }^{33}$.

Temos, aqui, três questões fundamentais e decisivas para o desenvolvimento de uma AT: seu objeto material (o homem); seu ponto de vista ou, na linguagem clássica, seu "objeto formal" (o homem em sua relação com Deus); seu método (a revelação cristã). Elas dizem respeito à identidade mais profunda e radical de uma antropologia teológica cristã. Todos os temas ou assuntos abordados e desenvolvidos nesta disciplina dizem respeito ao ser humano em sua respectividade e relação com Deus a partir de Jesus Cristo. Por isso mesmo, pode-se dizer que estas três questões constituem, em sua unidade, uma espécie de método fundamental ou de pressupostos epistemológicos fundamentais da $A T$.

No entanto, se em princípio essas questões podem parecer óbvias e tranquilas, afinal trata-se de uma antropologia (ser humano) teológica (respectiva a Deus) cristã (respectiva a Jesus Cristo), efetivamente e na prática são muito mais complexas e problemáticas do que parecem. Nem o que seja o ser humano em sua totalidade e complexidade é algo claro e consensual no mundo contemporâneo; nem a abordagem teológica do ser humano é algo tranqüilo em nossa cultura; nem sequer a abordagem teológica do ser humano a partir de Jesus Cristo é algo tão simples e evidente na teologia cristã.

${ }^{33}$ L.F. LADARIA, Introdução à antropologia teológica. Op. cit., p. 11. 
Daí que a identidade da $A T$, tanto no que diz respeito ao seu objeto material, quanto no que diz respeito ao seu ponto de vista, quanto ainda no que diz respeito a sua especificidade cristã, apresenta-se como uma identidade problemática, no sentido etimológico da palavra ${ }^{34}$, isto é, como algo que, por não ser óbvio nem tranquilo, lança-nos diante da tarefa de explicitá-la e justificá-la. Nessa tarefa, somos, então, confrontados, de imediato, com essas três grandes dificuldades que se constituem, ao mesmo tempo, em três grandes desafios para a reflexão teológica: a complexidade e irredutibilidade da realidade humana (objeto material), a possibilidade de uma abordagem estritamente teológica da antropologia (ponto de vista) e a abordagem teológica da antropologia a partir da vida concreta de Jesus de Nazaré a quem confessamos como Cristo (método). É o próximo passo da nossa reflexão.

\section{III - Dificuldades e desafios epistemológicos}

Tendo explicitado, a partir do texto de Ladaria, os pontos essenciais e fundamentais para a determinação e formulação do estatuto teórico da disciplina $A T$, resta-nos enfrentar ou pelo menos formular de modo adequado as dificuldades e os desafios epistemológicos referentes e cada um deles.

1. Antes de tudo, a dificuldade e o desafio concernentes ao objeto material da $A T$ : o ser humano em sua complexidade e irredutibilidade. Como bem indica Ladaria, no texto acima referido, se, por um lado, a expressão "antropologia" remete indiscutivelmente ao "homem", por outro lado, dada a complexidade que caracteriza essa realidade, ela acaba adquirindo um sentido profundamente "ambíguo". De modo que não basta afirmar que a $A T$ trata do ser humano. É preciso explicitar o ponto de vista sob o qual o ser humano é abordado nessa disciplina, o que implica reconhecer a existência e legitimidade de outros pontos de vista e, mesmo, a articulação e interação desses diversos pontos de vista, uma vez que todos eles dizem respeito a essa realidade concreta que é o ser humano.

Uma visão panorâmica da história da filosofia ${ }^{35}$ ajudaria imensamente na percepção tanto da complexidade da realidade humana quanto dos limites e reducionismos de sua abordagem ao longo da história. Diferentes aspectos ou dimensões da vida humana foram sendo explicitados e destacados de modo

\footnotetext{
${ }^{34}$ Pro-blema. Do grego pro-ballo: arrojar/atirar/lançar algo "ante" (Cf. X. ZUBIRI, Inteligencia y razón. Alianza Editorial, Madrid, 1983, pp. 64, 307, 315).

${ }^{35}$ Cf. H.C. LIMA VAZ, Antropologia filosófica I. Loyola, São Paulo, 1991, pp. 25-154.
} 
mais ou menos unilateral: dimensão racional, dimensão política, dimensão teologal, dimensão subjetiva, dimensão histórica, dimensão técnica, dimensão material, dimensão corpórea, dimensão sexual etc. Se o pensamento antigo insistiu na inserção do homem no cosmos; se o pensamento medieval enfatizou sua relação com Deus; se o pensamento moderno destacou muito sua irredutibilidade e suas capacidades teóricas e práticas; o pensamento contemporâneo, por um lado, alargou o horizonte moderno destacando aspectos da vida humana até então pouco desenvolvidos ou mesmo desvalorizados (corporeidade, sensibilidade, sexualidade etc.), e, por outro lado, para além da modernidade, "graças" à crise ecológica, reassumiu a dimensão natural da vida humana, tomando o homem como parte da natureza (horizonte ecológico ou sócioambiental ${ }^{36}$. Tudo isso tem repercutido imensamente, de modo mais ou menos positivo, na abordagem que a teologia vem fazendo do ser humano ao longo da história, dado o caráter contextual de toda teologia. E tudo isso deve ajudar na reflexão teológica atual sobre o ser humano: seja, negativamente, evitando cair em qualquer reducionismo; seja, positivamente, acolhendo e integrando as diferentes contribuições para o conhecimento da realidade humana.

De modo que, no que diz respeito ao "objeto material" da $A T$, é preciso considerar tanto a complexidade que caracteriza a realidade humana, quanto a especificidade de seu enfoque ou de sua abordagem. Ela tem que saber que seu enfoque é um enfoque entre outros e tem que ser capaz de dialogar e interagir com outros enfoques. Com bem afirma Ladaria, "a revelação cristã não pretende de modo algum ser a única fonte de conhecimento sobre o homem. Antes, ela pressupõe expressamente o contrário. Sem perder nada da especificidade teológica, a reflexão cristã sobre o homem deve enriquecer-se com os dados e as intuições provenientes da filosofia e das ciências humanas" ${ }^{\prime 3}$, bem como das mais diferentes formas e fontes de saber. E, levando em conta a sensibilidade e os desafios próprios do contexto em que vivemos, a $A T$ tem que ficar particularmente atenta contra os reducionismos espiritualistas, individualistas e antropocentristas. Dito positivamente, ela tem que levar muito em conta as dimensões corpórea, comunitária e natural/cósmica da vida humana.

${ }^{36}$ Cf. M.A. OLIVEIRA, "Ecologia, ética e libertação". In. IDEM, Tópicos sobre dialética. EDIPUCRS, Porto Alegre, 1997, pp. 173-202; IDEM, "Ampliação do sentido da libertação". In. IDEM, Diálogos entre razão e fé. Paulinas, São Paulo, 2000, pp. 153-167.

${ }^{37}$ L.F. LADARIA, Op. cit., p. 12. 
Assim, compreendendo e assumindo a realidade humana em sua complexidade e irredutibilidade, a reflexão teológica poderá avançar na explicitação e formulação da dimensão estritamente teologal e teológica da vida humana, tanto em sua especificidade quanto em sua interação com as outras dimensões da vida humana. Por mais que essa dimensão, precisamente enquanto dimensão, isto é, enquanto algo que mensura a realidade humana sob um determinado aspecto, seja inseparável das demais dimensões, ela tem sua especificidade e, enquanto tal, é irredutível às outras dimensões. $E$, aqui, precisamente, está o "objeto material" da $A T$. Ela não trata da realidade humana sem mais e em sua totalidade. Essa é uma realidade muito complexa e é abordada por diversas áreas do saber. A $A T$ se dedica ao estudo da dimensão teologal e teológica da vida humana, isto é, daquela dimensão que diz respeito à respectividade e à relação do ser humano com Deus. Esse é seu objeto material.

2. Como se vê, a determinação e formulação do "objeto material" da $A T$ envolvem, já, a problemática de seu ponto de vista ou de seu objeto formal e, assim, obriga-nos a enfrentar as dificuldades e os desafios epistemológicos inerentes a essa abordagem no contexto em que vivemos. E, como indicávamos acima, a abordagem propriamente teológica da antropologia não é nada tranquila em nossa cultura. Seja por sua negação mais ou menos direta e explícita; seja pela pluralidade e complexidade de sua abordagem. Concentremo-nos, aqui, no primeiro aspecto do problema.

Se em outras épocas históricas a realidade de Deus era algo aceito sem dificuldade e era, inclusive, a realidade a partir da qual em última instância tudo se tornava inteligível e compreensível, no mundo moderno, sobretudo nos centros de poder e nas camadas ilustradas, ela deixou de ser evidente, foi colocada sob suspeita e até mesmo negada. Pensemos, aqui, a título de exemplo, naqueles a quem Paul Ricoeur denomina os "mestres da suspeita": Feuerbach, Marx, Nietzsche e Freud ${ }^{38}$.

Com isso, a abordagem do ser humano do ponto de vista de sua respectividade e relação com Deus tornou-se também problemática. E problemática não só no sentido de que essa respectividade e relação do homem com Deus deixou de ser evidente, mas, mais radicalmente, no sentido de ser posta sob "suspeita" e, inclusive, de ser negada. De modo que a abordagem do homem pôde ser feita prescindindo de Deus e até mesmo em contraposição a ele.

${ }^{38}$ Cf. P. RICOUER, O conflito das interpretações. Res, Porto-Portugal, pp. 148, 147, 100; M.A. OLIVEIRA, Filosofia transcendental e religião. Ensaio sobre a filosofia da religião em Karl Rahner. Loyola, São Paulo, pp. 13-61; U. ZILLES, Filosofia da religião. Paulus, São Paulo, 2002. 
Antropologia e teologia apareceram, neste contexto, muitas vezes, como duas ciências não apenas autônomas, mas contrapostas, a ponto de que "a única relação entre as duas só poderá ser o conflito excludente ou a mútua redução"39. Ulpiano Vázquez resume e formula a objeção à possibilidade de uma "aliança" entre antropologia e teologia nos seguintes termos: "A teologia e a antropologia são discursos não só histórica como, sobretudo, formalmente heterogêneos" 40 . Historicamente, no sentido da "não contemporaneidade do discurso teológico e do discurso antropológico" ${ }^{41}$. Formalmente, isto é, do ponto de vista de sua "conformação interna e principial", no sentido de que "o mesmo assunto é pensado e tratado de maneira diferente" 42 por cada um deles: "o referencial primeiro e último, o sol que permite orientar-se, encontrar o sentido da realidade e a sintaxe ou a articulação desse sentido no discurso que pretende dizer o real" é, na teologia, Deus e, na antropologia, o homem ${ }^{43}$.

Essa objeção, "que pode ser feita, por motivos diferentes, tanto a partir da teologia como a partir da antropologia"44, pressupõe e se fundamenta, em última instância, numa concepção do homem (antropologia) e de Deus (teologia) que se contrapõem e se negam mutuamente. Nesta concepção, é claro, não há lugar ou possibilidade para uma $A T$, uma vez que ela implica, na formulação de Ulpiano Vázquez, uma "aliança" entre antropologia e teologia.

A questão reside em saber se essa concepção antropológica e teológica resiste a uma análise mais completa e consequente da realidade humana e da experiência de Deus que são a base e o princípio do discurso antropológico e teológico. Noutras palavras, trata-se de ver se a realidade humana não tem uma dimensão que envolve e dá acesso à realidade de Deus (dimensão teologal da antropologia $)^{45}$ e se a experiência de Deus não implica necessariamente o ser

\footnotetext{
${ }^{39}$ U. VÁZQUEZ MORO, Op. cit., p. 167.

${ }^{40}$ Ibidem, pp. 166 s.

${ }^{41}$ Ibidem, p. 167. "O termo teologia [...] surgiu na Grécia na primeira metade do século IV a.C. [...] A palavra 'teologia’ possuía, pois, 22 séculos de história e tinha garantido para si uma primazia incontestada, propriamente régia, na universidade da discursividade humana, quando Kant, em 1781, escreveu que todas as perguntas metafísicas, morais ou religiosas devem ser referias à antropologia e por ela respondidas" (Ibidem).

${ }^{42}$ Ibidem, p. 168.

${ }^{43}$ Ibidem, p. 167.

${ }^{44}$ Ibidem, p. 166.

${ }^{45}$ Foi o que tentaram demonstrar, dentre outros, e de modos bem distintos, Karl Rahner (Cf. K. RAHNER, Oyente de la palabra. Fundamentos para una filosofia de la religión. Op. cit.) e Xavier Zubiri (Cf. X. ZUBIRI, El hombre y Dios. Alianza Editorial, Madrid, 2003; IDEM, El problema filosófico de la historia de las religiones. Alianza Editorial, Madrid, 2006; IDEM, El problema
} 
humano (dimensão antropológica da teologia) ${ }^{46}$. Mas isto extrapola os limites e as possibilidades desta reflexão.

Em todo caso, a afirmação de uma $A T$ passa pela afirmação de uma "aliança" entre antropologia e teologia. Ela depende tanto da afirmação da realidade de Deus e da realidade do ser humano, quanto da afirmação da respectividade entre ambas as realidades, ainda que essa respectividade seja distinta em cada caso $^{47}$. Negar a Deus ou afirmá-lo à custa do ser humano ou mesmo como algo que nada tenha a ver com ele, é negar a possibilidade de uma $A T$.

Há basicamente duas formas de negar a Deus. Uma, mais teórica, direta e explícita: ateísmo. Outra, mais prática, indireta e sutil: idolatria. Mas também é possível afirmar a realidade de Deus de tal modo que se acabe negando a realidade humana. Seja através de um maniqueísmo espiritualista mais ou menos radical (espírito X matéria; bom X mau) que para afirmar a Deus tem que negar o homem. Seja através da instrumentalização ideológica da religião em função de interesses econômicos, políticos, culturais, de gênero etc., o que, em última instância, consiste na idolatria, isto é, na absolutização ou no endeusamento dos próprios interesses travestidos de deuses (ídolos), mesmo que (normalmente!) às custas dos interesses dos outros ou até de suas próprias vidas (os ídolos necessitam de sacrifícios...). Sem falar que a própria negação da realidade de Deus é, em si mesma, negação da realidade humana. Primeiro, na medida em que nega uma dimensão fundamental da realidade humana (ateísmo). Segundo, na medida em que absolutiza/endeusa certos interesses, submetendo e sacrificando a eles até a vida humana (idolatria).

Convém considerar com um pouco mais de atenção essas duas formas fundamentais de negação da realidade de Deus e do ser humano que são o ateísmo e a idolatria, destacando as características de cada uma e a diferença entre elas.

No que diz respeito ao ateísmo, aparentemente é a forma mais radical de negação da realidade de Deus, o maior inimigo das religiões e o maior perigo para a salvação da humanidade. Afinal, nega direta e explicitamente a realidade de Deus; denuncia e combate abertamente a religião; nega de modo mais ou menos radical uma transcendência na história. Na prática, como

\footnotetext{
teologal del hombre: Cristianismo. Alianza Editorial, Madrid, 1999).

${ }^{46}$ Esse ponto foi particularmente destacado por Rahner e adquiriu um amplo consenso no conjunto da teologia nas últimas décadas, não obstante os acentos, as ponderações e a diversidade de abordagens e formulações.

${ }^{47}$ Enquanto a respectividade de Deus ao homem diz respeito à sua revelação e ao seu conhecimento, a respectividade do homem a Deus diz respeito à sua própria essência.
} 
reconhece o Concílio Vaticano II, provavelmente não seja bem $\operatorname{assim}^{48} \mathrm{e}$, além de ser em boa medida produzido ou provocado pelos crentes ${ }^{49}$, tem forçado, mediante a suspeita religiosa, um processo de purificação e desideologização da religião. Por isso mesmo, convém abordar o mais objetivamente possível sua posição com relação ao problema de Deus e da religião, explicitando sua postura, assumindo o que tenha de verdadeiro e confrontando o que tenha de falso ou de parcial - que termina sendo uma forma de falsificação.

Quanto à idolatria, além de ser uma forma muito sutil de negação da realidade de Deus, afinal não nega explícita e formalmente a Deus, parece, em princípio, um fenômeno historicamente superado. A não ser para aqueles que, mediante uma leitura fundamentalista da Escritura, reduzem a idolatria à fabricação e à veneração de imagens ou a atitude de quem não participa das coisas da Igreja. Na prática, ela é muito mais atual, complexa e eficiente do que parece. Basta ver os frutos que produz: o Deus a quem servimos se manifesta no modo como vivemos e pelos frutos que produzimos (1 Jo 2, 6). E tem uma característica muito peculiar. A idolatria diz respeito, igualmente, a ateus e a crentes - a própria crença, não obstante sua ortodoxia formal, pode se tornar uma prática idolátrica - e encontra na vida dos "crentes" um terreno muito fértil porque convive, sem maiores problemas, com a confissão formal e ortodoxa de

\footnotetext{
${ }^{48}$ Ateísmo é uma expressão e uma realidade muito mais complexa do que parece. "Pela palavra ateísmo designam-se fenômenos bastante diversos entre si. Enquanto Deus é expressamente negado por uns, outros pensam que o homem não pode afirmar absolutamente nada sobre ele. Alguns, porém, submetem a exame o problema de Deus por tal método, que parece carecer de sentido. Muitos, ultrapassando indevidamente os limites das ciências positivas, ou sustentam que só por esse processo científico se explicam todas as coisas, ou, ao contrário, já não admitem de modo algum nenhuma verdade absoluta. Alguns exaltam o homem a tal ponto que a fé em Deus se torna como que enervada e dão a impressão de estar mais preocupados com a firmação do homem que com a negação de Deus. Outros se representam um Deus de tal modo que aquela fantasia, que eles repudiam, de modo algum é o Deus do evangelho. Alguns não abordam sequer o problema de Deus: parece não sentirem nenhuma inquietação religiosa e nem atinarem porque deveriam preocupar-se com a religião. Além disso, o ateísmo se origina não raramente ou de um protesto violento contra o mal no mundo, ou do caráter do próprio absoluto que se atribui indevidamente a alguns homens, de tal modo que sejam tomados por Deus" $(G S, 19)$.

49 "Os próprios fiéis arcam sobre isso muitas vezes com alguma responsabilidade. Pois o ateísmo, considerado no seu conjunto, não é algo inato mas antes originado de causas diversas, entre as quais se enumera também a reação crítica contra as religiões e em algumas religiões sobretudo contra a religião cristã. Por esta razão, nesta gênese do ateísmo, grande parte podem ter os crentes, enquanto, negligenciando a educação da fé, ou por uma exposição falaz da doutrina, ou por faltas na sua vida religiosa, moral e social, se poderia dizer deles que mais escondem que manifestam a face genuína de Deus e da religião" (GS, 19).
} 
Deus $^{50}$. Pode confessar com a boca o Deus de Jesus Cristo e, na prática, servir ao deus-dinheiro, ao deus-poder, ao deus-fama, ao deus-religião etc.

Se o ateísmo é uma postura predominantemente intelectivo-teórica (consciência, ideologia, razão etc.), não obstante seu caráter e suas implicações práticas; a idolatria é uma postura predominantemente práxica (o mais determinante na vida), embora, como toda práxis, tenha um momento intelectivo essencial que deva ser desenvolvido. Mais que afirmação/negação formal de Deus, há que se ver como Deus é negado ou afirmado ou que Deus é afirmado ou negado na vida de uma pessoa ou de uma comunidade.

Tudo isso torna a abordagem teológica da antropologia - ponto de vista ou objeto formal da $A T$ - extremamente complexa, problemática e desafiante.

3. Mas isso não é tudo. As dificuldades e os desafios não acabam aqui. Além dessa dificuldade mais fundamental que é a afirmação da dimensão teologal da vida humana, ligada a certas correntes do pensamento moderno e aos centros de poder, há outra dificuldade que diz respeito à especificidade cristã da $A T$. E, em certo sentido, essa dificuldade é até mais atual, complexa e desafiante. Primeiro, porque o ambiente cultural em que vivemos é muito menos avesso e hostil ao "religioso", relativizando o decreto da "morte de Deus" e do "fim da religião" e suscitando o que alguns chamam de "retorno do sagrado". Segundo, pela pluralidade e complexidade que caracterizam o "religioso" e o "sagrado" em nosso tempo, relativizando e dificultando enormemente sua caracterização e determinação. Não é nada fácil neste contexto dizer em que consiste o teologal e o teológico da vida humana. Terceiro, porque a própria tradição teológica cristã em seu diálogo com a filosofia greco-helenista acabou relativizando excessivamente a vida concreta de Jesus de Nazaré em função da determinação de sua essência permanente e imutável. De modo que, seja pelo caráter abstrato, difuso e até comercial do religioso em nosso tempo, seja por sua formulação histórica nos termos da filosofia greco-helenista na tradição teológica cristã, não é nada fácil nem tranquilo falar da respectividade e relação do homem com Deus a partir de Jesus de Nazaré. É o terceiro ponto ou aspecto da problemática do estatuto teórico da $A T$. Aquilo que Ladaria denomina de "método", isto é, o cominho que é preciso seguir para alcançar esse objetivo: partir da vida de Jesus de Nazaré, segundo as Escrituras.

${ }^{50}$ Cf. G. GUTIÉRREZ, O Deus da vida. Loyola, São Paulo, 1992, pp. 75-93; F. TABORDA, Nas fontes da vida cristã: uma teologia do batismo-crisma. Loyola, São Paulo, 2001, pp. 75-105. 
Certamente, sempre se afirmou e se continua afirmando na teologia cristã que a revelação de Deus atinge seu cume e sua plenitude na vida de Jesus Cristo. E, como consequência, em princípio, todos parecem estar de acordo em que a $A T$ se faz a partir dessa revelação que tem seu centro e seu cume em Jesus Cristo. No entanto, além disso não ser tão evidente nos discursos teológicos sobre Deus e sobre o homem que se produziram ao longo da história, funciona, muitas vezes, mais como afirmação meramente formal ou como princípio de intenção do que como princípio conformador e configurador do discurso teológico e antropológico.

Em seu último livro, publicado postumamente, sobre $O$ Espírito Santo e a tradição de Jesus, Comblin recolhe e reafirma a crítica à tradição teológica desenvolvida sob o cânone da filosofia grego-helenista. Embora carregando o tom na oposição entre o Deus dos filósofos (gregos) e o Deus de Jesus, destaca com acerto as consequências negativas desse fato para a teologia cristã, particularmente no que diz respeito ao caráter histórico-práxico da revelação cristã. Embora afirme que "Deus se revela em Jesus", na prática, essa teologia acaba partindo do "conceito filosófico de Deus dos filósofos gregos", submetendo a ele a própria revelação cristã de Deus e, assim, de alguma forma, ocultando o Deus de Jesus ${ }^{51}$. Também González Faus ${ }^{52}$ advertiu contra essa tentação e esse perigo para a teologia cristã. $E$ tanto com relação à cristologia ${ }^{53}$, quanto com relação ao discurso cristão sobre Deus ${ }^{54}$ e sobre o homem ${ }^{55}$. O perigo, aqui, consiste em "aproximar-se de Jesus com uma idéia predeterminada" de Deus e do homem. Dessa forma, diz ele, "impedimos que o acontecimento de Jesus nos ensine algo decisivo [sobre Deus e] sobre nós mesmos" $"$.

${ }^{51}$ Cf. J. COMBLIN, O Espírito Santo e a tradição de Jesus. NHANDUTHI, São Bernardo do Campo, 2012, pp. 99s, 179-196. "Ao adorar a filosofia como fundamento, a teologia mudava a estrutura da revelação. Em lugar de partir de Jesus partia de um conceito de Deus alheio, estranho, cósmico, e ia objetivar a realidade de Deus, colocado como uma categoria numa escala de ser, como o ser supremo. Deixava de lado a presença de Deus no íntimo de tudo e de todos os seres humano. Fazia de Deus um ser imutável, atemporal, muito distante dos homens e da sua criação. Essa filosofia dava como objeto do pensamento o ser. A categoria ser ficava como metodologia. Concentrava tudo nos seres, objeto da revelação. Mas na Bíblia não se dá valor ao ser, mas ao agir. O que faz o objeto da reflexão é o agir, as mudanças, as novidades. Nenhuma das categorias filosóficas é adequada. Elas deixam de lado o que Jesus disse e fez" (Ibidem, p. 187).

${ }^{52}$ Cf. J.I. GONZÁLEZ FAUS, Acesso a Jesus. Ensaios de teologia narrativa. Loyola, São Paulo, 1981.

${ }^{53}$ Cf. Ibidem, pp. 7-23.

${ }^{54}$ Cf. Ibidem, pp. 139-160.

${ }^{55}$ Cf. Ibidem, pp. 161-178.

${ }^{56}$ Cf. Ibidem, p. 161. 
$\mathrm{Na}$ verdade, esse tem sido um perigo e uma tentação constantes na história da teologia no passado, mas também no presente. E isso, inclusive, quando se afirma explicitamente a intenção de falar de Deus e do homem a partir de Jesus Cristo. Daí que não baste afirmar a centralidade de Jesus Cristo para o discurso teológico e antropológico cristãos. Isso a tradição teológica sempre fez. É preciso levar a sério o caráter histórico da revelação cristã e falar de Deus e do ser humano a partir da vida concreta de Jesus de Nazaré, o Cristo, tal como aparece na Sagrada Escritura.

O Concílio Vaticano II, tomando a escritura como que "a alma de toda teologia" (DV 24; OT 16), favoreceu e impulsionou a redescoberta do caráter histórico da revelação e, com isso, a formulação do discurso teológico em categorias práxico-históricas. Isso possibilitou e facilitou a redescoberta da densidade teológica da vida concreta de Jesus de Nazaré como lugar fundamental da revelação do mistério de Deus e do mistério do ser humano - algo extremamente relevante e decisivo para a $A T$.

No que diz respeito concretamente ao discurso teológico sobre o ser humano, a Constituição Pastoral Gaudium et Spes, de modo particular nos números 10 e 22, como afirma Ladaria, teve o grande mérito de estabelecer o "princípio" e indicar um "caminho para a construção de uma $A T$ completa e para a consolidação da disciplina sob forma unitária" - ainda que nem sempre tenha sido consequente com esse "princípio" e esse "caminho" 57 . Em todo caso, essa foi, sem dúvida alguma, a grande contribuição do Concílio para a disciplina $A T$ : "o mistério do homem só se torna claro verdadeiramente no mistério do Verbo encarnado"; "na mesma revelação do mistério do Pai e de seu amor, Cristo manifesta plenamente o homem ao homem e lhe descobre sua altíssima vocação" (GS 22). De modo que, para se falar cristãmente do homem em sua respectividade e relação com Deus, é preciso se voltar para a vida concreta de Jesus de Nazaré, em quem o Verbo de Deus se fez carne.

Permanece, em todo caso, o desafio de desenvolver de modo consequente um discurso teológico sobre o ser humano a partir da vida de Jesus de Nazaré. E esse desafio se desdobra em dois momentos. Em primeiro lugar, levando em conta as diferentes perspectivas e os diferentes interesses teóricos que orientaram e determinaram a elaboração do discurso teológico ao longo da história (natureza, sentido, práxis) ${ }^{58}$, é preciso discernir que horizonte teórico

\footnotetext{
${ }^{57}$ L.F. LADARIA, Op. cit., pp. 26-28.

58 Para uma aproximação mais ampla e fundamental da problemática, cf. W. KASPER, Introducción a la Fe. Sigueme, Salamanca, 1982, pp. 40-43; J.B. LIBÂNIO, Formação da
} 
apreende de modo mais adequado a vida de Jesus de Nazaré e, consequentemente, permite explicitar mais e melhor a especificidade cristã da antropologia. Em segundo lugar, é preciso desenvolver sistematicamente e de modo consequente a visão e o modo cristão de ser humano a partir daquela vida concreta na qual reconhecemos e confessamos a revelação plena e definitiva do mistério de Deus e do mistério do homem.

De modo que a problemática da especificidade cristã da $A T$ se desenvolve em três momentos distintos, mas mutuamente implicados e articulados: Jesus Cristo como "princípio" e "caminho" da $A T$; horizonte teórico mais adequado para a preensão da vida de Jesus e para a formulação cristã da dimensão teológica da vida humana; desenvolvimento sistemático da visão e do modo cristão do ser humano. Mas isso extrapola os limites e as pretensões desse trabalho.

Temos, então, explicitados e formulados, ainda que a modo de esboço, os três grandes desafios epistemológicos da $A T$, tal como foram propostos e formulados por Ladaria: seu "objeto material" (o ser humano), seu "ponto de vista" ou seu "objeto formal" (a relação do homem com Deus) e seu "método" ou sua especificidade cristã (revelação em Jesus Cristo). No fundo, eles se resumem a duas grandes questões que, em sua unidade, constituem uma espécie de método fundamental ou de pressupostos epistemológicos fundamentais da $A T$ : seu assunto (dimensão teologal da vida humana ou respectividade e relação do homem com Deus) e seu método (a partir da vida concreta de Jesus de Nazaré).

\section{A modo de Conclusão: Antropologia Teológica na "Crise da Modernidade"}

Ao tratarmos do contexto que provocou a "concentração antropológica" ou mesmo a "virada antropológica" na reflexão teológica, chamávamos atenção para o caráter "tardio" desse fenômeno no contexto mais amplo da reviravolta antropológica que caracterizou o mundo moderno.

consciência crítica 1: subsídios filosófico-culturais. Vozes, Petrópolis, 1984; A. GONZÁLEZ, “El significado filosófico de la teología de la liberación”. In J. COMBLIN - J.I. GONZÁLEZ FAUS J. SOBRINO, Cambio social y pensamiento cristiano en América Latina. Trotta, Madrid, 1993, pp. 145-160. Para uma aproximação da problemática no caso concreto da teologia dos sacramentos, cf. V. CODINA, "Sacramentos". In: I. ELLACURÍA - J. SOBRINO, Mysterium liberationis: conceptos fundamentales de la Teología de la Liberación”. Trotta, Madrid, 1994, pp. 267-294; F. TABORDA, "Sacramentos, práxis e festa: crítica e auto-crítica", Perspectiva Teológica 21 (1989) pp. 85-99; IDEM, "Vida cristã e sacramentos: para uma pastoral sacramental teologicamente atualizada”, Perspectiva Teológica 21 (1989) pp. 227-236. 
Agora, a modo de conclusão, queremos apontar, sem maiores desenvolvimentos, para uma consequência que bem pode ser entendida como outro significado desse caráter tardio e que ameaça e desafia tanto as conquistas da modernidade como a própria identidade da $A T$. É que a concentração ou a virada antropológica na teologia se dá não apenas séculos depois do início desse fenômeno no Ocidente, mas também no momento em que cresce a consciência de seus limites e de suas consequências negativas na vida humana e no conjunto da natureza, ou seja, no auge da crise da modernidade. A modernização da teologia se dá, portanto, no contexto da crise da modernidade. $\mathrm{E}$ tanto no que diz respeito a determinados processos de modernização ${ }^{59}$, quanto, mais radicalmente, no que diz respeito à modernidade enquanto tal ${ }^{60}$.

Com isso, a teologia é desafiada não simplesmente a explicitar e desenvolver a dimensão teologal e teológica da vida humana, para além de qualquer reducionismo materialista ou racionalista, mas também a assumir a dimensão natural da antropologia, superando certas formas de antropocentrismo que acabam negando a materialidade da vida humana e reduzindo a natureza a mero recurso a ser apropriado e comercializado. Ela tem que afirmar simultaneamente a dimensão teológica e natural da vida humana. Continua tratando do ser humano em sua relação com Deus (dimensão teológica da vida humana). Mas deve estar atenta contra qualquer reducionismo, particularmente aquele que contrapõe sem mais vida humana $X$ natureza (dimensão natural da vida humana).

O tema é complexo e não podemos desenvolvê-lo aqui. Em todo caso, cremos ser útil e necessário mencioná-lo para evitar ou ao menos advertir contra certos antropocentrismos modernos, mas também contra certos ecologismos que, repetindo os reducionismos modernos, ainda que pelo avesso, acabam contrapondo vida humana e natureza e, cinicamente, igualando o ser humano aos demais seres da natureza ou até tratando-o (senão teoricamente, na prática) como inferior e menos importante que certos "micos leões dourados"...

\footnotetext{
${ }^{59}$ Cf. M.A. OLIVEIRA, Ética e racionalidade moderna. Loyola, São Paulo, 1993; IDEM, Ética e economia. Ática, São Paulo, 1995; IDEM, Desafios éticos da globalização. Paulinas, São Paulo, 2001; B.S. SANTOS, Um discurso sobre as ciências. Cortez, São Paulo, 2010; IDEM (org.), Conhecimento prudente para uma vida decente; "um discurso sobre as ciências" revisitado. Cortez, São Paulo, 2006.

${ }^{60}$ L. BOFF, Nova era: a civilização planetária. Ática, São Paulo, 1994; IDEM, Ecologia: grito da terra, grito dos pobres. Ática, São Paulo, 1995; IDEM, A voz dos arco-íris. Latraviva, Brasília, 2000; M.A. OLIVEIRA, "Ecologia, ética e libertação". Op. cit.; IDEM, "Ampliação do sentido da libertação". Op. cit,.
} 
Assim como a concentração antropológica na teologia não se entende simplesmente nem em última instancia a partir e em função da reviravolta antropológica que caracteriza o mundo moderno; tampouco a crise da modernidade significa sem mais uma crise nem muito menos uma negação da dimensão antropológica de toda teologia e, concretamente, dessa área ou disciplina que é a $A T$. O ser humano continua no centro da história da salvação e, neste sentido, pode-se falar de certo antropocentrismo na teologia cristã. Mas o ser humano que está no centro da história da salvação tem uma dimensão natural essencial e é parte da própria natureza. Enquanto tal, não pode ser considerado independentemente nem muito menos em oposição à natureza. Noutras palavras, o que está em crise não é a centralidade do ser humano no cosmos nem muito menos na história da salvação, mas um modo de entender e configurar essa centralidade, em oposição a outros seres humanos e ao conjunto da natureza.

Importa, aqui, em todo caso, afirmar e explicitar a dimensão teológica da vida humana (assunto da $A T$ ) a partir da vida de Jesus de Nazaré (método da $A T$ cristã), tendo sempre presente que esta é apenas uma dimensão da vida humana. Uma dimensão entre outras e em interação com outras dimensões, dentre as quais está a dimensão natural ou ecológica. Nisto, precisamente, consiste a problemática da disciplina $A T$, objeto de nossa consideração neste artigo.

\section{Referências Bibliográficas}

BEOZZO, J. O. (org.). O Vaticano II e a Igreja latino-americana. Paulinas, São Paulo, 1985.

BOFF, C. "Teologia da libertação e volta ao fundamento", REB 268 (2007) pp. 1001-1022.

, Teoria do método teológico. Vozes, Petrópolis, 1998.

BOFF, L. A voz dos arco-íris. Latraviva, Brasília, 2000.

, Ecologia: grito da terra, grito dos pobres. Ática, São Paulo, 1995.

, Nova era: a civilização planetária. Ática, São Paulo, 1994.

BRAMBILLA, F. G. Antropologia teologica. Queriniana, Brescia, 2009.

CODINA, V. "Sacramentos". In: I. ELLACURÍA - J. SOBRINO, Mysterium liberationis: conceptos fundamentales de la Teología de la Liberación". Trotta, Madrid, 1994, pp. 267-294. 
COMBLIN, J. O Espírito Santo e a tradição de Jesus. NHANDUTHI, São Bernardo do Campo, 2012.

EICHER, P. Die anthropologische Wende. Karl Rahners philosophischer Weg vom Wesen des Menschen zur personalen Existez. Universitätsverlag, Freiburg, 1970.

ELISONDO, F. “Antropologia”. In: C. FLORISTÁN-SAMANES - J.J. TAMAYO-ACOSTA, Dicionário de Conceitos Fundamentais do Cristianismo. Paulus, São Paulo, 1999, pp. 23-32.

ELLACURÍA, I. "En torno al concepto y a la idea de liberación”. In. IDEM, Escritos Teológicos I. UCA, San Salvador, 2000, pp. 629-657.

FABRO, C. Karl Rahner e l'ermeneutica tomista. La risoluzione-dissoluzione della metafísica nell'antrpologia. Editrice Divus Thomas, 1972. , La svolta antropológica di Karl Rahner. Rusconi, Milano, 1974.

FLICK, M. - ALSZEGHY, Z. Fondamenti di una Antropologia Teológica. Fiorentina, Firenze, 1982.

GONZÁLEZ, A. "El significado filosófico de la teología de la liberación". In COMBLIN, J. - GONZÁLEZ FAUS, J. I. - SOBRINO, J. Cambio social y pensamiento cristiano en América Latina. Trotta, Madrid, 1993, pp. 145-160.

GONZÁleZ FAUS, J. I. Acesso a Jesus. Ensaios de teologia narrativa. Loyola, São Paulo, 1981.

GUTIÉRREZ, G. O Deus da vida. Loyola, São Paulo, 1992.

KANT, I. Crítica da razão pura. Nova Cultural, São Paulo, 1996 (Os Pensadores).

, Lógica. Tempo brasileiro, Rio de Janeiro, 2003.

KASPER, W. Introducción a la Fe. Sigueme, Salamanca, 1982.

LADARIA, L. F. Antropologia teológica. UPCM, Madrid - PUG, Roma, 1983. , Introdução à antropologia teológica. Loyola, São Paulo, 1998.

LIBÂNIO, J. B. Formação da consciência crítica 1: subsídios filosóficoculturais. Vozes, Petrópolis, 1984.

LIMA VAZ, H. C. Antropologia filosófica I. Loyola, São Paulo, 199. 
, "Religião e modernidade filosófica", Síntese Nova Fase 53 [1991] pp. 147-165.

MONDIN, B. Antropologia teológica: história, problemas, perspectivas. Paulinas, São Paulo, 1986.

OLIVEIRA, M. A. Ética e racionalidade moderna. Loyola, São Paulo, 1993. , Ética e economia. Ática, São Paulo, 1995. , Desafios éticos da globalização. Paulinas, São Paulo, 2001. , Diálogos entre razão e fé. Paulinas, São Paulo, 2000, pp. 153-167. , Filosofia transcendental e religião. Ensaio sobre a filosofia da religião em Karl Rahner. Loyola, São Paulo, 1984. , Tópicos sobre dialética. EDIPUCRS, Porto Alegre, 1997.

OLIVEIRA, M. A. - ALMEIDA, C. O Deus dos filósofos modernos. Vozes, Petrópolis, 2002.

PANNENBERG, W. Anthropologie in theologischer Perspective. Vandenhoeck \& Ruprecht, Göttingen, 1983

, Was ist der Mensch? Die Anthropologie der Gegenwart im Lichte der Theologie. Vandenhoeck \& Ruprecht, Göttingen, 1995.

PAULO VI, "Discurso pronunciado na nona sessão conciliar". In: VATICANO II, Mensagens, discursos e documentos. Paulinas, São Paulo, 2007, pp. 118-125.

RAHNER, K. Oyente de la palabra. Fundamentos para una filosofia de la religión. Herder, Barcelona, 1976.

, "Reflexões fundamentais sobre a antropologia e a protologia no conjunto da teologia". In: J. FEINER - M. LOEHRER, Mysterium Salutis II/2. Vozes, Petrópolis, 1972, pp. 6-19.

, Teologia e antropologia. Paulinas, São Paulo, 1969.

, A voz dos arco-íris. Latraviva, Brasília, 2000.

RATZINGER, J. - MISSORI, V. A fé em crise? O Cardeal Ratzinger se interroga. EPU, São Paulo, 1985.

RICOUER, P. O conflito das interpretações. Res, Porto-Portugal.

RITO, H. Introdução à teologia. Vozes, Petrópolis, 1999, p. 17. 
SANTOS, B. S. (org.). Conhecimento prudente para uma vida decente; "um discurso sobre as ciências" revisitado. Cortez, São Paulo, 2006. , Um discurso sobre as ciências. Cortez, São Paulo, 2010.

SEGUNDO, J. L. “Críticas y autocríticas de la teología de la liberación”. In: COMBLIN, J. - GONZÁLEZ FAUS, J.I. - SOBRINO, J. Cambio social y pensamiento cristiano en América Latina. Trotta, Madrid, 1993, pp. 215-236.

TABORDA, F. Nas fontes da vida cristã: uma teologia do batismo-crisma. Loyola, São Paulo, 2001.

, "Sacramentos, práxis e festa: crítica e auto-crítica", Perspectiva Teológica 21 (1989) pp. 85-99.

, "Vida cristã e sacramentos: para uma pastoral sacramental teologicamente atualizada", Perspectiva Teológica 21 (1989) pp. 227-236.

VÁZQUEZ MORO, U. “Teologia e antropologia: aliança ou conflito?”, Perspectiva Teológica 60 (1991) PP. 163-174.

ZILLES, U. Filosofia da religião. Paulus, São Paulo, 2002.

ZUBIRI, X. El hombre y Dios. Alianza Editorial, Madrid, 2003.

, El problema filosófico de la historia de las religiones. Alianza Editorial, Madrid, 2006.

, El problema teologal del hombre: Cristianismo. Alianza Editorial, Madrid, 1999.

, Inteligencia y razón. Alianza Editorial, Madrid, 1983.

Francisco de Aquino Júnior

Doutor em teologia pela Westfälische Wilhelms -Universität de Münster - Alemanha Professor de teologia da Faculdade Católica de Fortaleza

Recebido em 08/04/13

Aprovado em 19/06/13 